\title{
Activity Elderly Peer Group
}

\author{
Eka Rokhmiati Wahyu Purnamasari ${ }^{1}$, Saeful Gunardi ${ }^{2}$, Dina Febrina ${ }^{3}$ \\ ' Program Studi Keperawatan Sekolah Tinggi Ilmu Kesehatan Indonesia Maju (STIKIM) \\ 2,3Program Studi Ners Sekolah Tinggi IImu Kesehatan Indonesia Maju (STIKIM) \\ Email: ${ }^{1}$ eka.rokhmiati@gmail.com, ${ }^{2}$ saiful.gunardi@gmail.com, ${ }^{3}$ febrinadina25@gmail.com
}

\begin{abstract}
Abstrak
Usia Lanjut usia (Lansia) akan terjadi berbagai penurunan fisik, psikologis, kognitif dan hubungan sosial. Tujuan dari penelitian ini meningkatkan minat Lansia ke Posbindu dengan memberikan variasi aktivitas yang bermanfaat agar kualitas hidupnya lebih terjaga. Pos Pelayanan Terpadu (Posbindu) merupakan wadah beraktivitas Lansia sejumlah total sampel 68 di wilayah RW 05, dibantu oleh Kader dan di fasilitasi oleh Puskesmas. Aktivitas atau Kegiatan bermanfaat secara bersama yaitu; life review reminiscence, senam, kontrol kesehatan dan penyuluhan kesehatan mengenai cara perawatan penyakit kronis (Diabetes Mellitus dan Hipertensi). Sebelum adanya variasi aktivitas, kunjungan Lansia berkurang dan sesudah adanya variasi aktivitas, minatnya meningkat ke Posbindu. Dibuktikan dengan uji paired T Test $\mathrm{P}$ Value 0.002; menunjukan variasi aktivitas meningkatkan minat Lansia berkunjung ke Posbindu. Peran tenaga kesehatan yaitu; Perawat memfasilitasi kader, untuk memberikan variasi aktivitas secara kontinyu serta memberikan ilmu dan informasi kesehatan guna meningkatkan minat Lansia di RW 05 Ciganjur Jagakarsa Jakarta Selatan.
\end{abstract}

Kata kunci : Lansia, Posbindu, Kader, Aktivitas

\begin{abstract}
Elderly was old ages will occur a variety of physical, psychological, cognitive and social relations decline. The purpose of this study was provided beneficial activities for the elderly so that their quality of life was maintained. The Integrated Service Post (Posbindu) was an Elderly activity container with a total sample of 68 in the RW 05 area, assisted by KADER and facilitated by the Puskesmas. Useful activities together were; life review reminiscence, gymnastics, health control and health education on how to treat chronic diseases (Diabetes Mellitus and Hypertension). By used pretest-posttest without control group design and paired $T$ test with $P$ value 0.002 ; show diverse activities increase the interest of the elderly visiting Posbindu. The role of health workers, especially nurse, continuously provided education of health as knowledge and information for kader and elderly people in RW 05 Ciganjur Jagakarsa, South Jakarta.
\end{abstract}

Keywords : Elderly, Posbindu, Kader, Activity 


\section{Pendahuluan}

Usia Lanjut atau disingkat dengan Lansia adalah usia dimana sesorang mengalami perubahan dan kemungkinan akan terjadi penurunan fungsional baik fisik, finansial, dan sosial. Dikatakan usia lanjut jika berusia diatas 65 tahun. Pada lansia Penyakit terbanyak dan sering kali di derita karena proses menua (degeneratif) adalah penyakit hipertensi essensial, katarak dan diabetes. ${ }^{1}$

Peran keluarga dan perawat akan sangat membantu bagi lansia yang menderita penyakit degeneratif. Lansia butuh dukungan keluarga, seperti penerimaan kondisi lansia serta cara bersikap pada lansia. Anggota keluarga dan peran perawat perlu memberikan dukungan emosional, agar lansia merasa mendapat perhatian dan dukungan. ${ }^{2}$

Disamping keluarga dan perawat, masyarakat sekitar lansia juga perlu mendukung kesehatan lansia. Masyarakat sekitar inilah yang sering disebut dengan Kader. Kader merupakan bagian masyarakat yang terpenting dalam peningkatan derajat kesehatan lansia. Tehnik pelatihan pada kader terbukti dapat meningkatkan kesehatan pada lansia disekitarnya, khususnya pengurangan tingkat depresi. Tingkat depresi seringkali terjadi pada lansia yang kurang melakukan aktivitas dan sosialisasi dalam hidupnya. ${ }^{3}$

Depresi yang lama dan terjadi pada lansia serta berkepanjangan akan berdampak pada penurunan sistem imun dan mempercepat progresivitas terjadinya gangguan kesehatan pada lanjut usia. ${ }^{4}$ Selain depresi penurunan akitivitas pada lansia mengakibatkan terjadi penuranan fungsi muskuloskeletal termasuk fungsi motorik. $^{5}$

Peningkatan dan perbaikan kesehatan sangat dipengaruhi oleh adanya panutan. Panutan atau role model bagi lansia akan menjadikan lansia lebih bersemangat dalam lingkup keluarga dan peer group. ${ }^{6}$ Pemanfaatan pos pembinaan terpadu (POSBINDU) adalah tempat berkumpulnya lansia. Peer group ini merupakan pemicu bagi lansia untuk rajin memeriksakan kesehatan, di samping adanya kader dan pantauan petugas kesehatan. $^{7}$ Tujuan dari penelitian ini adalah memberikan variasi aktivitas secara kontinyu serta memberikan ilmu dan informasi kesehatan guna meningkatkan minat Lansia di RW 05 Ciganjur Jagakarsa Jakarta Selatan.

\section{Metode}

Penelitian ini adalah penelitian eksperimental dengan desain one group pretest -posttest without control group design. Pre test dilakukan dengan membagikan kuisioner dan aktivitas pemeriksaan kesehatan kepada lansia yang ada. Peneliti lalu memberikan aktivitas peer group seperti life review reminiscence, senam, kontrol kesehatan, penyuluhan kesehatan mengenai cara perawatan penyakit kronis (Diabetes Mellitus dan Hipertensi), lansia yang ada di wilayah RW 05 Ciganjur sebanyak 68 orang.

Setelah kurang lebih selama 2 minggu Lansia diberikan kuisioner kembali. Minat Lansia meningkat datang ke Posbindu karena berbagai variasi aktivitas.

Kriteria inklusi pada penelitian in adalah lansia yang tidak memiliki cacat fisik dan lansia yang menetap tinggal di wilayah RW 05.

Univariat pada penelitian ini adalah jenis kelamin, pendidikan status perkawinan, jenis penyakit yang di derita, dan media informasi. Penelitian bivariate uji paired $T$ Test dengan membandingkan minat lansia ke Posbindu sebelum dan sesudah adanya variasi aktivitas di Posbindu.

\section{Hasil}

Penelitian ini dilakukan dari bulan awal Januari hingga akhir Februari 2019 di Wilayah RW 05 Ciganjur Jagakarsa, Jakarta Selatan. Penelitian dilakukan oleh peneliti dengan mengikutsertakan mahasiswa Profesi Ners STIKIM. 
Hasil penelitian ini memuat berbagai karakteristik Lansia yang ada di RW 05 Ciganjur.

Tabel 1. Analisis Univariat

\begin{tabular}{llll}
\hline Variabel & Kategori & n & \% \\
\hline Jenis Kelamin & Laki-laki & 18 & 27 \\
& Perempuan & 50 & 73 \\
Pendidikan & SMP & 15 & 22 \\
& SMA & 53 & 78 \\
Perkatus & Menikah & 10 & 15 \\
Jenis penyakit & Janda/Duda & 58 & 85 \\
& Hipertensi & 40 & 59 \\
& Diabetes & 19 & 28 \\
& Katarak & 7 & 10 \\
& Lainnya (asma, & 2 & 3 \\
& osteoporosis, penyakit & & \\
Media & kulit) & & \\
informasi & Edaran & & 10 \\
& Lainnya & 7 & \\
& pengumuman, arisan, & & \\
& komunikasi & & \\
& keluarga) antar & & \\
& & & \\
\hline
\end{tabular}

Hasil univariat jenis kelamin di dominasi oleh perempuan yaitu sebanyak 50 orang $(73 \%)$. Pendidikan lansia RW 05 rata rata memiliki pendidikan sekolah menengah atas (SMA) sebesar 78\%. Status Perkawinan Lansia, lebih banyak yang tidak memiliki pasangan sebesar $85 \%$ (duda/janda). Timbulnya penyakit kronis menyebabkan lansia mengalami penurunan fungsi fisik dan rentan terhadap penyakit sering dikeluhkan yang terbanyak hipertensi yaitu $59 \%$.

Tabel 2. Pengaruh Aktivitas Variasi pada peer grup meningkatkan minat Lansia Ke Posbindu Lansia

\begin{tabular}{llllll}
\hline Variabel & $\begin{array}{c}\sum \\
\text { sebelum } \\
\text { variasi } \\
\text { aktivitas }\end{array}$ & $\%$ & $\begin{array}{c}\sum \\
\text { sebelum } \\
\text { variasi } \\
\text { aktivitas }\end{array}$ & $\%$ & Pv \\
\hline $\begin{array}{l}\text { Aktivitas } \\
\text { lansia }\end{array}$ & 10 & 14,7 & 58 & 85,29 & 0,002 \\
\hline
\end{tabular}

Hasil analisis t-test diketahui bahwa terdapat hubungan antara sebelum dan sesudah dilakukan variasi aktivitas dalam posbindu. Peran perawat penting untuk melakukan pembinaan bagi kader yang ada di wilayah RW 05 (16), sebagai bentuk dukungan dalam pembinaan asuhan keperawatan khususnya implementasi kegiatan yang bervariasi untuk Posbindu.

\section{Pembahasan}

Lansia wanita lebih banyak jumlahnya dibandingkan dengan lansia pria. Banyaknya Lansia wanita, dikarenakan Lansia wanita banyak lebih pada penerimaan diri atau bersyukur serta bersabar, pola pikir positif dan dukungan sosial. ${ }^{8}$ Kecenderungkan Lansia pria lebih malu untuk bercerita dibanding dengan Lansia wanita. Terlebih jika Lansia pria telah ditinggalkan oleh pasangannya. Lansia wanita lebih mudah terbuka, lebih mau bercerita terhadap kebutuhan yang diinginkan. Lansia memiliki kebutuhan sebagaimana individu pada umumnya, yaitu kebutuhan dasar, psikis, sosial, dan spiritual. $^{9}$ Kebutuhan dasar seperti rasa kasih sayang dan penghargaan dari anak anaknya. Seringkali banyak Lansia yang Senin hingga Jumat momong cucu. Kegiatan momong cucu mereka jadikan sarana untuk menghibur diri mereka bagi mereka yang telah kehilangan pasangan. Walau mereka seringkali mengatakan lelah dan tidak dapat mengikuti kegiatan Posbindu di wilayah RW 05, yang Seringkali kegiatan dilakukan di hari Senin -Jumat.

Tingkat Pendidikan Walau berada dalam pendidikan menengah atas, seringkali pengetahuan lansia merawat penyakitnya berdasarkan pengalaman pribadi dan pengalaman dari orangtuanya. Tentu saja hal ini kurang sesuai untuk saat ini .Pengaruh pendidikan berpengaruh terhadap penerimaan informasi, makin tinggi pendidikan lansia akan semakin baik didalam berkomunikasi dan berinteraksi didalam peer grup tersebut. ${ }^{10}$

Status perkawinan Lansia pada lansia turut mendukung angka kejadian kesakitan. Menikah dan memiliki pasangan dapat menurunkan angka kesakitan dan menurunkan angka kejadian Lansia berkunjung ke pelayanan kesehatan. ${ }^{11}$ 
Pasangan membuat sesorang dapat dijadikan teman cerita dan teman berdiskusi seumurnya dibanding yang tidak memiliki pasangan. ${ }^{3}$ Akan tetapi adakalanya Lansia tidak mau merepotkan anak dan keluarga nya dan seringkali perasaan tersebut mereka simpan sendiri. ${ }^{12}$

Informasi untuk mengingatkan dilakukan kader saat ini adalah dengan mengirimkan send message short (SMS), model seperti ini memudahkan bagi lansia yang seringkali lupa untuk ke posbindu. Jika 2 kali tidak datang maka kader akan mendatangi rumah lansia untuk menanyakan ketidakhadiran mereka. Para Kader pun mengatakan sudah berusaha maksimal membina Posbindu, mereka mengatakan lansia yang hadir tidak konsisten dan kontinyu.

Peran Kader sangat penting dalam kegiatan Posbindu, karena kedekatan dan kebersamaan. Penting adanya peningkatkan ilmu dan informasi bagi kader. Informasi dan ilmu oleh kader haruslah sesuai dengan azas keilmuan yang sudah tervalidasi. Tentunya ilmu dan informasi yang di dapat haruslah dari sumber yang mumpuni.

Perlunya kegiatan di usia senja nya mencegah depresi pada Lansia. ${ }^{6}$ Kegiatan senam yang dilakukan di Posbindu adalah senam hipertensi. Saat senam raut wajah Lansia ceria dan tersenyum. Senam terbukti menurunkan laju peredaran darah pada lansia terhadap systole, distole, dan denyut nadi serta stroke volume. ${ }^{13}$ Kegiatan lain yang disukai oleh Lansia adalah bercerita, apalagi menceritakan perjalanan hidupnya life review reminiscence. Metode ini efektif bagi lansia untuk mengurangi dimensia, ${ }^{14}$ akan tetapi tidak semua suka akan metode ini karena beda tipe kepribadian. Kepribadian yang ekstrovet senang sekali ada metode ini, tetapi metode ini bertahap dapat dicoba bagi yang memiliki tipe introvet. ${ }^{10}$

Lansia yang memiliki gangguan kesehatan ini menandakan seringnya penyakit yang tidak ditangani cara perawatannya dengan baik, akan menimbulkan komplikasi. ${ }^{15}$

Beberapa literatur mengatakan pembinaan dan pendidikan bagi kader akan meningkatkan kemampuan kader dalam membina Lansia. $^{2}$ Pelatihan dan pembinaan bagi kader penting untuk update ilmu, pemberian modul untuk penduan dan buku pegangan kader. Dengan adanya pengetahuan melalui informasi yang diberikan, maka menghasilkan ide bagi kader untuk mengadakan aktivitas yang bervariatif dan terbukti meningkatkan minat Lansia untuk datang ke Posbindu.

\section{Kesimpulan}

Hasil penelitian diatas membuktikan bahwa Lansia membutuhkan perhatian yang serius, ini akan meningkatkan kualitas hidup Lansia. Meningkatkan kualitas hidup pada Lansia dengan memberikan wadah kegiatan dan informasi kesehatan. Wadah tersebut adalah Posbindu, kegiatan di dalamnya tidak melulu pemeriksaan rutin saja. Modifikasi dan variasi kegiatan di Posbindu dapat berupa senam, penyuluhan, life story dan kegiatan rohani. Kegiatan yang bervariasi dan modifikasi akan meningkatkan minat bagi Lansia untuk datang ke Posbindu. Beberapa hal yang dapat dilakukan untuk meningkatkan partisipasi lansia dalam Posbindu antara lain dengan memberikan pelatihan khusus Lansia bagi Kader Posbindu, menyiapkan modul pegangan mengenai aktivitas yang dapat dilakukan oleh Lansia bagi para Kader, Memberikan penyuluhan bagi Masyarakat sekitar mengenai pemberdayaan Lansia di RW 05 Ciganjur.

\section{Daftar Pustaka}

1. Rohmah A.I.N, Purwaningsih B. Quality of Life Elderly. 2012;120-32.

2. Nuraeni A, Handayani PA, Riani S. Group Discussion Dalam Pemberian Dukungan Keluarga Lansia. 2016;

3. Prayogi B. Depresi Pada LANSIA Di UPT PSLU BLITAR ( Peer Group Support to Decrease the Depression Level of Elderly at UPT PSLU Blitar ). 2016;3(3):253-6. 
4. Kurnianto S, Purwaningsih, Nihayati HE. Penurunan Tingkat Depresi pada Lansia dengan Pendekatan Bimbingan Spiritual. J Ners. 2011;6:156-63.

5. Oliveira TA, Fernando S, Duarte P, Araújo L. Relationship Between Elderly Body Mass Index And Motor. 25(4):1-9.

6. Kristyaningsih D. Keluarga Dengan Tingkat Depresi Pada Lansia. J Keperawatan. 2011;1(1):1-18.

7. Purdiyani BagianPendidikan Kesehatan dan Ilmu Perilaku F. Pemanfaatan Pos Pembinaan Terpadu Penyakit Tidak Menular (Posbindu Ptm) Oleh Wanita Lansia Dalam Rangka Mencegah Penyakit Tidak Menular Di Wilayah Kerja Puskesmas Cilongok 1. J Kesehat Masy [Internet]. 2016;4(1):23563346. Available from: http://ejournals1.undip.ac.id/index.php/jkm

8. Kurniasari KTL. Kualitas perempuan lanjut usia yang melajang. J Psikol Pendidik dan Perkemb [Internet]. 2013;1(3):152-9. Available from: http://www.google.co.id/journal.unair.ac.id

9. Sa'adah, Nurus (Sunan, UIN Yogyakarta K. Menata Kehidupan Lansia: Suatu Langkah Responsif untuk Kesejahteraan Keluarga ( Studi pada Lansia Desa Mojolegi Imogiri Bantul Yogyakarta). J Ilm Sosiol Agama. 2015;9(2):49-70.

10. Jamil M. Satisfaction of Social Interaction On The Old Age With Personality Type Mokhtar Jamil Harapan hidup penduduk Indonesia ratarata mengalami peningkatan dari tahun ke tahun . Data yang diperoleh dari Biro Pusat Statistik pada tahun 2005 , usia harapan hidup.
2012;3:171-82.

11. Zhang J, Xu L, Li J, Sun L, Ding G, Qin W, et al. Loneliness and health service utilization among the rural elderly in shandong, China: A cross-sectional study. Int $\mathbf{J}$ Environ Res Public Health. 2018;15(7):1-11.

12. Sessiani LA, Psikologi F. Studi Fenomenologis tentang Pengalaman Kesepian dan Kesejahteraan Subjektif pada Janda Lanjut Usia. 2018;13(2):203-36.

13. Pinto RR, Karabulut M, Poton R, Polito MD. Acute resistance exercise with blood flow restriction in elderly hypertensive women: Haemodynamic, rating of perceived exertion and blood lactate. Clin Physiol Funct Imaging. 2018;38(1):17-24.

14. Lin HC, Yang YP, Cheng WY, Wang JJ. Distinctive effects between cognitive stimulation and reminiscence therapy on cognitive function and quality of life for different types of behavioural problems in dementia. Scand J Caring Sci. 2018;32(2):594-602.

15. Rosyada A, Trihandini I. Determinan Komplikasi Kronik Diabetes Melitus pada Lanjut Usia Determinan of Diabetes Mellitus Chronic Complications on Elderly. Dapertemen Biostat dan Ilmu Kependud Fak Kesehat Masy Univ Indones. 2010;3:395-401.

16. Chavez KS, Dwyer AA, Ramelet AS. International practice settings, interventions and outcomes of nurse practitioners in geriatric care: A scoping review. Int J Nurs Stud [Internet]. 2018;78(October 2016):6175. Available from: https://doi.org/10.1016/j.ijnurstu.2017.09.010 